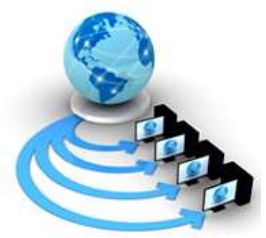

Volume 10, No. 1, January-February 2019

ISSN No. 0976-5697

International Journal of Advanced Research in Computer Science

RESEARCH PAPER

Available Online at www.ijarcs.info

\title{
AN ANALYSIS OF TASK SCHEDULING ALGORITHM IN CLOUD ENVIRONMENT
}

\author{
Zoheb Hasan \\ M.Tech Scholar \\ Department of CSE \\ Jamia Hamdard, New Delhi
}

\author{
Suraiya Parveen \\ Assistant Professor \\ Department of CSE \\ Jamia Hamdard, New Delhi
}

\begin{abstract}
Cloud Computing has become a well-liked computing paradigm that has gained huge attention in delivering on-demand services. Task scheduling in cloud computing is a crucial issue that has been well researched and lots of algorithms are developed for identical. However, the goal of most of those algorithms is to attenuate the general completion time (i.e., makespan) while not trying into step-down of theoverall price of the service (referred as budget). Moreover, several of them are applicable to single-cloud atmosphere. During this paper the present state of Task scheduling algorithms has been mentioned and compared on the premise of assorted planning parameters like execution time, throughput, makespan, resource utilization, quality of service, energy consumption, interval and value.
\end{abstract}

Keywords:Cloud Computing; Task Scheduling; Multi-objective; Makespan;Total Cost; load balancing ,Energy efficient.

\section{INTRODUCTION}

Cloud computing is associate advance technology in recent years. A program runs on several connected computers at constant time in distributed system networks.[1]. National Institute of standard Technology(NIST) defines cloud computing may be a model for sanctionative convenient, ondemand network access to a shared pool of configurable computing resources (e.g. networks, servers ,applications and services) which will be discharged with minimal management effort or service supplier interaction. Cloud Computing provides everything as a service, the 3 basic service layers of cloud computing are: -

Infrastructure, Platform and Applications that area unit popularly cited as IaaS (Infrastructure as a Service), PaaS (Platform as a Service) and SaaS (Software as a Service) that helps business organizations, Organization establishments, government organizations in scaling down operational expenses [2].

Cloud computing deploy model comes in 3 forms: public clouds, private clouds and hybrid clouds [3].Private cloud is one within which the services and infrastructure area unit maintained on a personal network. Public cloud is one within which the services and infrastructure area unit provided off-site over the web. Hybrid cloud includes a range of public and personal choices with multiple suppliers. Currently cloud is employed to implement programing. Tasks area unit regular by user needs. Initially, programing algorithms were being enforced in grids. Grid performance is incredibly but the Cloud performance [4].The programing methods planned to beat the issues between user and resources. For big range of straightforward tasks once they execute one by one in cloud system will increase value|, price and also the cost is shrivelled if we've got little range of complicated tasks. Once the amount of users in cloud gets accumulated then the programing becomes tough. Therefore, there's a requirement to travel for a far better programing algorithm than existing one. Since cloud computing the various sorts of researches area unit occurring, the analysis space which incorporates cloud systems development and management, resource allocation and programing, security problems, cloud storage, measurability, program models then on. This may be done by scrutiny and evaluating the varied existing algorithms, thereby distinctive the loop holes within the existing algorithms. programing plays more necessary role in cloud computing [5].

\section{SCHEDULING PARAMETERS}

Various parameters are employed in this section to check various Scheduling algorithms:

\section{A. Execution time}

The execution time or computer hardware time of a given task is outlined because the time spent by the system execution that task, as well as the time spent execution runtime or system services on its behalf.

B. latency

The go ontime between the top of associate inquiry or demand on an automatic data processing system and also the starting of a response. The latency is that the addition of the service time and waiting time. Technically latency is that the time of system takes to react to a given input.

C. Make span

It is employed in producing. It is the time distinction between the beginning and end of a sequence of jobs and tasks. If we have a tendency to don't scale back the build span of that product the order wouldn't shipped on time.

D. Energy Consumption 
It is the consumption of energy or power. It is conjointly outlined in some quarters because the use of energy as a stuff within the method of producing utilities.

E. Throughput

It refers to what quantity information may be transferred from one location to a different in an exceedingly given quantity of your time. A benchmark is employed to live turnout. Generally terms it's the speed of production or the speed at that one thing may be processed. It is used to measure the performance of Hard Drives and RAM.

F. Scalability

It is the capacity of a computer application or product to continue to function well when it is changed in size or volume in order to meet a user need. The increasing demands and growing amount of the work is known as scalability.

G. Resource utilization

Resource utilization is the application of a resource in such a way that increases throughput. The sources used to perform particular task. The objective is to maximize customer service levels, minimize lead times, and optimize inventory levels.

H. Load Balancing

It is especially important for networks where it is difficult to predict the number of requests that will be issued to a server. For using load balancing scheme busy web sites typically employ two or more web servers.

I. Fault tolerance

Fault tolerance is defined as how to provide, by redundancy, service complying with the specification in spite of faults having occurred or occurring. It is setup configurationthat prevent a computer network device from failing in the event of an unexpected problem or error.

J. Energy Consumption

Energy consumption is the amount of resource energy used to produce the output. Energy consumption should be minimal. The Cloud Computing environments require a huge quantity of information and communication technologies gear reminiscent of servers, storage devices, communication network instruments and patron terminals. Hence, it's clear that the standard use of Cloud Computing offerings will broadly make contributions to a fast increase on ICT vigor consumption.

$\mathrm{K}$.Performance

The accomplishment of a given task measured against preset identified requirements of completeness, cost, accuracy, and velocity. In computing performance is measured by the time and cost, a system ought to complete a user task in less time and minimum value of services. A performance ought to be thought of at each sideuser and supplier by programing formula.

\section{Quality of Service}

Best of supplier considers user involvement restrictions like meeting point in time, efficiency, execution worth, make span, so forth. Everything is made public in Service Level Agreement (SLAs) that may be a contract file outlined between the cloud user and cloud service supplier.

\section{III.VARIOUS TASK SCHEDULING ALGORITHMS}

In this section, various Task Scheduling algorithms are mentioned and connected programing parameters are highlighted as execs and cons. Table -1 presents overall analysis and comparison of those Task programing algorithms on the idea of those parameters. It consolidates totally different programing algorithms and corresponding parameters that they need supported.

1. Multi-Objective Task programing formula

Most of the programing algorithms minimize the makespan inconsiderately of reduction in price of services, these algorithms also are applied on single-cloud atmosphere. The formula mentioned in [5] considers each parameters, the makespan and price of service in an exceedingly multi-cloud atmosphere. It additionally considers the typical utilization of cloud resources. The Cloud Min-Min programing considers solely reduction of makespan and Profit primarily based Task sheduling (PBTS) considers solely price of services, none of them contemplate multiple parameters. Experiment and results shows that projected formula minimizes price and makespan at the same time and maximizes average utilization of resources.

\section{Multilevel Priority-Based Task programing}

Previous priority-based Task programing algorithms schedules tasks in keeping with the priority supported the scale of program. The computer hardware divides tasks into totally different levels and allocates the resources in step with the help necessities of the assorted tasks levels. The results of experiment show that this technique is powerful to manage structure task of workflows. This formula effectively reduces execution time and makespan. The projected formula chiefly emphasizes on freelance tasks of progress by determinative only 1 parameter, however it may be stretched for dependent tasks.

3. Load balancing Task scheduling Algorithm

For reducing the quality, most of the programing algorithms don't contemplate the load balancing which can seem uneven load. These algorithms don't contemplate the connection among task allotted and therefore the node load. If a task is allotted to associate degree full node, then the system performance can drastically decrease. The projected formula [7] is predicated on weighted random and feedback mechanism that assures that exceptional nodes wouldn't be weighed down and for general performance nodes have the capability to execute tasks. The formula will expeditiously stability the burden and balances the load of the unequal and full nodes among the opposite nodes within the Cloud Computing atmosphere.

4. Particle Swarm improvement primarily based Task Scheduling Algorithm

This formula [8] considers the necessities of dimensional Quality of Service (QoS). The equality of resource allocation results is chosen through Berger model. The formula makes changes within the Particle Swarm improvement (PSO) formula through correcting its limits dynamically. Then, it endorses a top quality of service primarily based dynamic particle swarm improvement (QoS-DPSO) formula. The experiment results show that the user tasks may be effectively dead and therefore the fairness in allocation of system resource may be achieved by this algorithm. The results of experiment recommend that this technique will expeditiously resolve Task programing downside in cloud computing atmosphere however it doesn't contemplate execution price and response time. 
5. Energy-Efficiency primarily based Task programing Algorithm

There is anenormous power consumption in cloud primarily based information centers, that semiconductor diode to attention on the Task programing to decrease the facility consumption. During this paper [9], a dynamic voltage and frequency scaling (DVFS) enabled Energy-efficient progress Task programing formula (DEWTS) has been planned, with the aim of acquire a lot of power drop on high of assures the standard of service (QoS). The formula divides the parallel tasks in workflows to the acceptable electronic equipment and use them at correct time to decrease power consumption and acquire demanded performance. Experimental outcome shows that the formula decreases the facility consumption by $45.5 \%$ in parallel tasks execution beside balances the performance of programing.

6. Cuckoo optimization primarily based Task Scheduling Algorithm

When a collection of tasks gain the cloud, the system is meant to reply to all or any of them as a result of it manages to achieve the shortest latent period. During this paper [10], Author uses Cuckoo formula to hold out amongst these controls. The reason for the planned technique is attaining Associate in Nursing order of process units such the time of responses to tasks is decreased. The Cuckoo formula uses variety of virtual machines and therefore the type of tasks, with the help of examining various orders of those machines, the planned approach allocates hosts to tasks in an exceedingly right manner. Because of short calculation and computer file that cause least dependency on computer file, makes the Cuckoo formula a lot of widespread. Due to levy flight general and native search will be done at the same time. This formula uses Cuckoo formula for load balance in cloud calculations that decrease interval of the system. During this formula bird nest is ready of calculate units, the population of birds is in relation with calculate units' order and every levy flight switches task from one machine to a different. Simulation effects show that the usage of Cuckoo formula for the aim of achieving the simplest order of process devices will cause progressed performance parameters.

7. Energy-Efficient primarily based Task Algorithm This planned inexperienced energy-efficient programing formula [11] is predicated on priority Task programing formula. The load of virtual machines and therefore the
Service Level Agreement (SLA) needed by user are used as parameters for priority to pick out VMs for execution tasks. This approach ensures the minimum demand of resources and limits the over resource usage by a task. This facility consumption of the server will be reducing once it's in idle state or low work through Dynamic Voltage Frequency Scaling (DVFS) technique. Hence, this technique will decrease the facility consumption of servers and enhance the resource utilization. The simulation shows that the facility dissipation during this technique will decrease by twenty third with compare to the tactic documented in [12].

8. Fault-Tolerant progress programing formula

The planned programing formula [13] choose tasks for execution on the premise of 2 estimating models on-demand and spot instances to chop down service price and at a similar time fulfill work point in time. The approach is vigorous counter to the performance variation of resources and additionally fault tolerant counter to the untimely death of spot instances. The formula uses just-in-time (JIT) and adaptive programing heuristic. The computer hardware calculates the slack time for every prepared job, the distinction between the vital path time and point in time. As job's slack time declines thanks to failure or deviation in performance of the system, this technique adaptively shifts dynamically user jobs to on-demand instances. The experimental outcomes illustrate that these heuristic lessens execution time by seventieth as compared to just one instance usage.

9. Adaptive Energy-Efficient Scheduling Algorithm

The traditional energy-efficient primarily based Task programing algorithms target a threshold to stable system performance and power consumption. However system parameters and application demand cannot flexibly be tailored by the random threshold that makes the programing outcomes instable. During this technique [14], authorproposed a two-phase adaptive Energy-efficient programing (AES), which contains the adaptive task replication policy with the Dynamic Voltage Scaling (DVS) technique. First of all, it planned Associate in Nursing adaptive threshold-enabled job replication strategy, that set ideal threshold, and second once any task has slack time then it selects the cluster of tasks on DVS-aided machines that may decrease voltage to decrease system power consumption. The experimental outcomes show that this technique will save power consumption and increase system performance.

\begin{tabular}{|c|c|c|c|c|c|c|c|c|c|c|c|c|}
\hline $\begin{array}{l}\text { Scheduling } \\
\text { Algorithm }\end{array}$ & 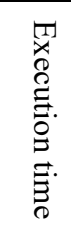 & 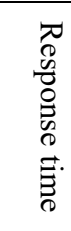 & 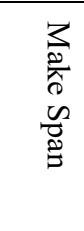 & 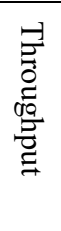 & 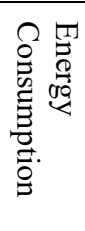 & 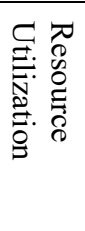 & 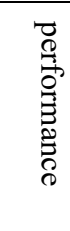 & 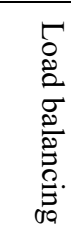 & 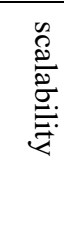 & 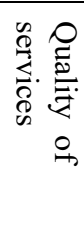 & § & 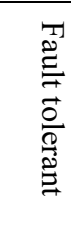 \\
\hline $\begin{array}{l}\text { Muti Objective } \\
\text { Task Scheduling } \\
\text { Algorithm }\end{array}$ & $\mathrm{N}$ & $\mathrm{N}$ & $\mathrm{Y}$ & $\mathrm{N}$ & $\mathrm{N}$ & $\mathrm{Y}$ & $\mathrm{N}$ & $\mathrm{N}$ & $\mathrm{N}$ & $\mathrm{Y}$ & $\mathrm{Y}$ & $\mathrm{N}$ \\
\hline $\begin{array}{l}\text { Load } \quad \text { Balancing } \\
\text { Task Scheduling } \\
\text { Algorithm } \\
\end{array}$ & $\mathrm{N}$ & $\mathrm{N}$ & $\mathrm{N}$ & $\mathrm{N}$ & $\mathrm{N}$ & $\mathrm{Y}$ & $\mathrm{Y}$ & $\mathrm{Y}$ & $\mathrm{Y}$ & $\mathrm{N}$ & $\mathrm{N}$ & $\mathrm{N}$ \\
\hline $\begin{array}{lr}\begin{array}{l}\text { Energy } \\
\text { based }\end{array} & \text { Tfficient } \\
\end{array}$ & $\mathrm{N}$ & $\mathrm{N}$ & $\mathrm{N}$ & $\mathrm{N}$ & $\mathrm{Y}$ & $\mathrm{Y}$ & $\mathrm{Y}$ & $\mathrm{N}$ & $\mathrm{N}$ & $\mathrm{Y}$ & $\mathrm{N}$ & $\mathrm{N}$ \\
\hline
\end{tabular}




\begin{tabular}{|c|c|c|c|c|c|c|c|c|c|c|c|c|}
\hline $\begin{array}{l}\text { Scheduling } \\
\text { Algorithm }\end{array}$ & & & & & & & & & & & & \\
\hline 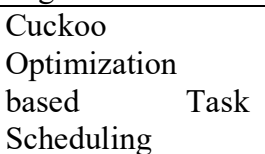 & $\mathrm{N}$ & $\mathrm{Y}$ & $\mathrm{N}$ & $\mathrm{N}$ & $\mathrm{N}$ & $\mathrm{N}$ & $\mathrm{Y}$ & $\mathrm{Y}$ & $\mathrm{N}$ & $\mathrm{N}$ & $\mathrm{N}$ & $\mathrm{N}$ \\
\hline $\begin{array}{lr}\text { Particle swam } \\
\text { optimization } \\
\text { based } \\
\text { Scheduling }\end{array}$ & $\mathrm{N}$ & $\mathrm{N}$ & $\mathrm{N}$ & $\mathrm{N}$ & $\mathrm{Y}$ & $\mathrm{N}$ & $\mathrm{N}$ & $\mathrm{N}$ & $\mathrm{Y}$ & $\mathrm{Y}$ & $\mathrm{N}$ & $\mathrm{N}$ \\
\hline $\begin{array}{l}\text { Multilevel } \\
\text { Priority based } \\
\text { Task Scheduling }\end{array}$ & $\mathrm{Y}$ & $\mathrm{N}$ & $\mathrm{Y}$ & $\mathrm{N}$ & $\mathrm{N}$ & $\mathrm{N}$ & $\mathrm{N}$ & $\mathrm{N}$ & $\mathrm{N}$ & $\mathrm{N}$ & $\mathrm{N}$ & $\mathrm{N}$ \\
\hline $\begin{array}{lr}\text { Adaptive } & \text { Energy } \\
\text { Efficient } & \text { Task } \\
\text { Scheduling } & \\
\text { Algorithm } & \end{array}$ & $\mathrm{N}$ & $\mathrm{N}$ & $\mathrm{N}$ & $\mathrm{N}$ & $\mathrm{Y}$ & $\mathrm{Y}$ & $\mathrm{Y}$ & $\mathrm{N}$ & $\mathrm{N}$ & $\mathrm{N}$ & $\mathrm{N}$ & $\mathrm{N}$ \\
\hline $\begin{array}{lr}\text { Online } & \\
\text { optimization for } \\
\text { Preemptive Task } \\
\text { Scheduling } \\
\text { Algorithm }\end{array}$ & $\mathrm{Y}$ & $\mathrm{N}$ & $\mathrm{N}$ & $\mathrm{N}$ & $\mathrm{Y}$ & $\mathrm{Y}$ & $\mathrm{Y}$ & $\mathrm{N}$ & $\mathrm{N}$ & $\mathrm{N}$ & $\mathrm{N}$ & $\mathrm{N}$ \\
\hline $\begin{array}{l}\text { Fault Tolerant } \\
\text { workflow } \\
\text { scheduling } \\
\text { algorithm }\end{array}$ & $\mathrm{Y}$ & $\mathrm{N}$ & $\mathrm{N}$ & $\mathrm{Y}$ & $\mathrm{N}$ & $\mathrm{N}$ & $\mathrm{N}$ & $\mathrm{N}$ & $\mathrm{N}$ & $\mathrm{N}$ & $\mathrm{N}$ & $\mathrm{Y}$ \\
\hline $\begin{array}{l}\text { Green energy } \\
\text { Efficient based } \\
\text { Task scheduing } \\
\text { Algorithm }\end{array}$ & $\mathrm{N}$ & $\mathrm{N}$ & $\mathrm{N}$ & $\mathrm{N}$ & $\mathrm{Y}$ & $\mathrm{Y}$ & $\mathrm{N}$ & $\mathrm{N}$ & $\mathrm{N}$ & $\mathrm{Y}$ & $\mathrm{N}$ & $\mathrm{N}$ \\
\hline
\end{tabular}

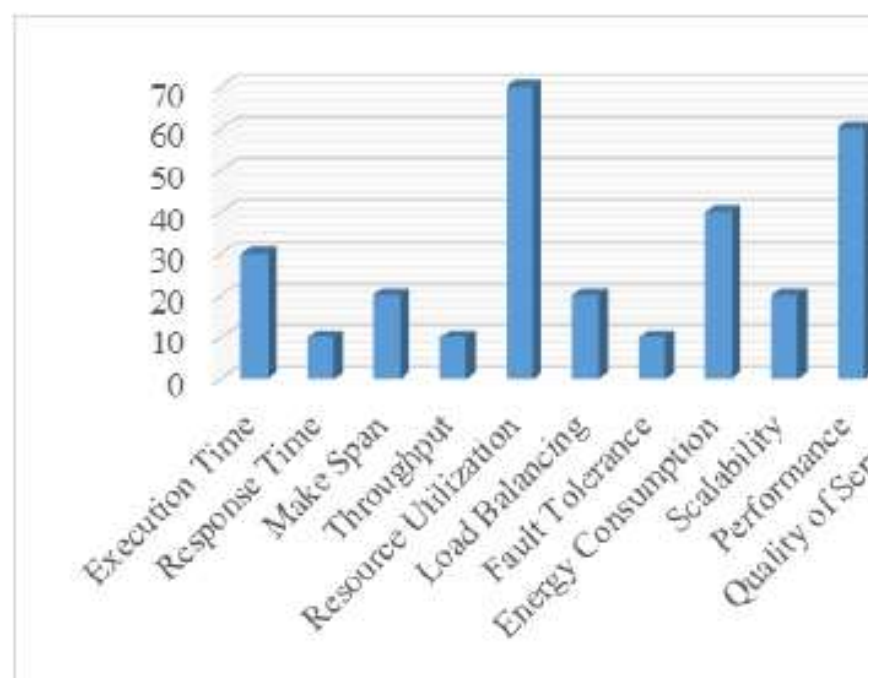

Fig 2.Proportion of scheduling characteristics supported by various discussed Task Scheduling algorithms

\section{PROBLEMS AND FUTURE DIRECTIONS}

The study of various cloud based mostly Task scheduling algorithms shows that Task planning plays a crucial role by providing measurability, on-demand resources, energy consumption, that increased the performance of the Cloud ADP system. Most of planning algorithms centered on the energy consumption and reduce price, however there's still lots of improvement is required that constitutes the Cloud
Computing towards the cloudcomputing. Most of the algorithms mentioned here, perform planning on the idea of 2 or 3 planning parameters. An efficient Task scheduling algorithm will be style by adding additional parameters to the prevailing algorithms which may enhance the system performance in close to future.

\section{CONCLUSION}

Task scheduling is incredibly vital fact for Cloud Computing to supply measurability, resource pooling and on-demand self-service, associate economical Task planning algorithm is needed. During this paper, recently developed Task scheduling algorithms in Cloud Computing surroundings are studied and varied within which Particle Swarm improvement and Cuckoo improvement based Task planning Algorithms are impressed from nature based algorithms and DVFS-enabled Energy-efficient progress, Green Energy-Efficient and Adaptive Energy-Efficient Task Scheduling Algorithms are supported energy consumption. From fig. two we can see that resource utilization and system performance are lined in sixty to seventy share of mentioned algorithms for improvement. Energy consumption and quality of service are improved in forty share of algorithms. however there's still lots of labor needed to enhance fault tolerance and cargo equalization. A Sufficient Task scheduling formula ought to facilitate the cloud system to satisfy all the necessities created within the contract of Service Level Agreement (SLA) between the cloud suppliers and client.

\section{REFERENCES}


[1] P. Mell and T. Grance, "The NIST definition of cloud computing", 2011.

[2] Q. Zhang, L. Cheng and R. Boutaba, "Cloud computing: state-of-the-art and research challenges", J Internet ServAppl, vol. 1, no. 1, pp. 7-18, 2010.

[3] B. Jennings and R. Stadler, "Resource Management in Clouds: Survey and Research Challenges", J NetwSyst Manage, vol. 23, no. 3, pp. 567-619, 2014.

[4] T. Mathew, K. Sekaran and J. Jose, "Study and analysis of various task scheduling algorithms in the cloud computing environment", 2014 International Conference on Advances in Computing, Communications and Informatics (ICACCI), 2014.

[5] S. Panda and P. Jana, "A multi-objective task scheduling algorithm for heterogeneous multi-cloud environment", 2015 International Conference on Electronic Design, Computer Networks \& Automated Verification (EDCAV), 2015.

[6] A. Bala and I. Chana, "Multilevel Priority-Based Task Scheduling Algorithm for Workflows in Cloud Computing Environment", Advances in Intelligent Systems and Computing, pp. 685-693, 2016.

[7] Z. Qian, G. Yufei, L. Hong and S. Jin, "A Load Balancing Task Scheduling Algorithm based on Feedback Mechanism for Cloud Computing", International Journal of Grid and Distributed Computing, vol. 9, no. 4, pp. 41-52, 2016.

[8] A. Xu, Y. Yang, Z. Mi and Z. Xiong, "Task Scheduling Algorithm Based on PSO in Cloud Environment", 2015 IEEE 12th Intl Conf on Ubiquitous Intelligence and Computing and 2015 IEEE 12th Intl Conf on Autonomic and Trusted Computing and 2015 IEEE 15th Intl Conf on Scalable Computing and Communications and Its Associated Workshops (UIC-ATC-ScalCom), 2015.

[9] Z. Tang, L. Qi, Z. Cheng, K. Li, S. Khan and K. Li, "An Energy-Efficient Task Scheduling Algorithm in
DVFS-enabled Cloud Environment", J Grid Computing, vol. 14, no. 1, pp. 55-74, 2015.

[10] A. Moradbeiky and V. Bardsiri, "A Novel Task Scheduling Method in Cloud Environment using Cuckoo Optimization Algorithm", International Journal of Cloud-Computing and Super-Computing, vol. 2, no. 2, pp. 7-20, 2015.

[11] C.Germain-Renaud, O.Rana "The Convergence Of Clouds, Grids, andAutonomics" IEEE Internet Computing 13 (6) (2009) 9.

[12] Karan D.Prajapati, Prof.PushpakRaval, MirenKaramta, Dr.M.B.Potdar"Comparison of Virtual Machine Scheduling algorithms in CloudComputing" International Journal of Computer Applications (0975-8887) 2013.

[13] Krishan Kant Lavania, Yogita Sharma, ChandreshBakliwal "A Review on Cloud Computind Model" InternationalJournal on Recent and Innovation Trends in Computing andCommunication ISSN 2321-8169 Volume: 1 Issue: 3 March 2013.

[14] AnjuBala, Dr.InderveerChana "A Survey of Various WorkflowScheduling Algorithms in Cloud Environment" 2nd InternationalConference on Information and Communication Technology November 2011 by IJCS Journal (26-30).

[15] M.Gokilavani, S.Selvi, C.Udhayakumar "A Survey on ResourceAllocation and Task Scheduling Algorithms in Cloud Environment" ISO9001:2008 Certified International Journal of Engineering and InnovativeTechnology (IJEIT) Volume 3, Issue 4, October 2013.

[16] Ke Liu, Hai Jin, Jinjun Chen, Xiao Liu, Dong Yuan, Yun Yang, "ACompromised-Time-Cost Scheduling Algorithm in SwinDeW-C forInstance-Intensive Cost-Constrained Workflows on Cloud Computing Platform" International Journal of High Performance ComputingApplications Volume 24 Issue 4, November $2010 \quad$ Pages445-456. 